\title{
Preparing to Be a Clinical Supervisor: Avoiding a "Trial by Fire" and Using Reflection
}

\author{
Lindsey E. Bloor ${ }^{1,2 *}$, Katherine A. Kitchen Andren ${ }^{1,2}$, Cathy J. Strader Donnell ${ }^{1,2}$ \\ ${ }^{1}$ Department of Psychiatry, VA Ann Arbor Healthcare System, Ann Arbor, MI, USA \\ ${ }^{2}$ Department of Psychiatry, University of Michigan Health System, Ann Arbor, MI, USA \\ Email: *Lindsey.bloor2@va.gov, Katherine.kitchen-andren@va.gov, Cathy.donnell@va.gov
}

How to cite this paper: Bloor, L. E., Andren, K. A. K., \& Donnell, C. J. S. (2018). Preparing to $\mathrm{Be}$ a Clinical Supervisor: Avoiding a "Trial by Fire" and Using Reflection. Psychology, 9, 809-819. https://doi.org/10.4236/psych.2018.94052

Received: March 21, 2018

Accepted: April 24, 2018

Published: April 27, 2018

Copyright (c) 2018 by authors and Scientific Research Publishing Inc. This work is licensed under the Creative Commons Attribution International License (CC BY 4.0).

http://creativecommons.org/licenses/by/4.0/

(c) (i) Open Access

\begin{abstract}
Clinical supervision is a distinct skill and role for psychologists, and providing supervision to psychology trainees is foundational to the field. While there is significant attention paid to the progression from trainee to competent therapist with this supervision, there appears a need to articulate models that foster growth from trainee or licensed clinician to effective clinical supervisor. Within psychology, data from the perspectives of trainees, licensed clinicians, and patients/clients have depicted the importance of high quality clinical supervision. These data also illuminate the need for potential models to teach the clinical supervisory role. This paper describes two Veterans Healthcare Administration (VHA) clinical training models that offer frameworks and processes for learning a new clinical role. Importantly, the frameworks utilize reflection, from both the medical student and motivational interviewing traditions, which aim to instill confidence and enhance quality as one utilizes new clinical skills and takes on the supervisory role.
\end{abstract}

\section{Keywords}

Clinical Supervision, Psychology, Learning/Training, Reflection

\section{Introduction}

Providing clinical supervision for psychology trainees is foundational in the field of clinical psychology. The American Psychological Association defines clinical supervision as a distinct professional practice, and in the field's more recent history, guidelines defining the elements of competent supervision have been outlined (American Psychological Association, 2014, 2015), including domains such as professionalism, ethical and legal considerations and supervisory relationship. Furthermore, there are clear guidelines that identify parameters on the clinical 
supervision provided, such as number of hours required weekly and format (e.g. face-to-face, individual, and group). While training to become a competent psychotherapist has a rich history with these guidelines and oversight, much less formalized training or guidance on how to become a competent clinical supervisor appears to exist. Thus, most psychologists have had to learn as they go or experience a "trial by fire" in becoming an effective clinical supervisor for trainees. This paper reviews existing literature, outlining a need for frameworks and processes to guide tiered supervision or supervision-of-supervision ("sup-of-sup") to learn the new professional role.

More recently, there are workshops, courses integrated into training programs, and a growing literature on theories or models of supervision and factors associated with adult learning (e.g., Sudak et al., 2015). These models typically focus on and assure the trainee's competency to develop case formulation and provide efficacious and ethical treatment to their patients. However, these do not highlight a process that can facilitate the development of a new effective supervisor. Given requirements that trainees must "demonstrate competence" in supervision as part of their training, the field of psychology might look more broadly and consider drawing from paradigms utilized in business management, the sports arena, and other related medical fields that offer training in supervision, mentorship, and coaching in order to inform this developmental process. This paper proposes two potential frameworks that draw on coaching and learning theories as practical guides for licensed clinicians to learn and/or practice in a new clinical supervisory role as well as to teach the supervisory role to trainees.

\section{Perspectives on the Supervisory Role}

Perspectives on supervision from the point of view of the psychology trainee are available. This descriptive literature provides sparse information about program or class structure and components or processes, but rather aims to understand the experience of learning to become a supervisor and inform supervisory needs and development (e.g., Borders \& Fong, 1994; Duffy \& Guiffrida, 2014; Gazzola, De Stefano, Thériault, \& Audet, 2013; Gazzola, De Stefanob, Theriault, \& Audet, 2014; Majcher \& Daniluk, 2009; Ögren, Boalt Boëthius, \& Sundin, 2008; Okafor, Wojciak, \& Helfrich, 2014; Sundin, Ögren, \& Boalt Boëthius, 2008). These perspectives highlight the unique facets of learning to be a supervisor, further confirming that becoming a competent clinical supervisor requires more training beyond showing competence as a therapist. In particular, a common theme among supervisor trainees was a sense of self-doubt, uncertainty, and lack of a sense of competence in assuming the new role as a supervisor (Borders \& Fong, 1994; Gazzola et al., 2013; Majcher \& Daniluk, 2009). Indeed, relationship and competence issues were the most prevalent supervisory issues ranked by supervisor trainees (i.e., counseling psychology doctoral students; Ellis, 2006). Key challenges identified in another study included "difficulty establishing a super- 
visory stance" and "managing the gatekeeping role," which the authors described as feeling discomfort related to having authority, evaluating competencies, and giving negative feedback (Gazzola et al., 2013). Trainees in other studies reported challenges associated with shifting the focus from the client to the counselor for whom supervision was provided (Borders \& Fong, 1994; Majcher \& Daniluk, 2009).

In addition to challenges experienced by supervisors-in-training, some work has focused on the positive aspects of training and factors that facilitate development of clinical supervisory skills (e.g., Gazzola et al., 2014; Majcher \& Daniluk, 2009). In one study, six counseling psychology doctoral students completing a supervision training course highlighted the importance of the relationship with their supervisor (i.e., the senior supervisor), including a safe, supportive, respectful working relationship, similar to a strong therapeutic alliance that is important in clinical outcomes (Majcher \& Daniluk, 2009). These trainees also described the benefit of ongoing reflection and feedback on their developing theoretical conceptualization and supervisory skills. Other tools for preparing supervisors-in-training have been described and include writing in weekly supervision journals to assist processing and managing the experiences of beginning a new supervisor role (Okafor et al., 2014). Writing supervision documentation notes (Bernard, 2014), formulating a supervision genogram (i.e., symbolizing a supervisee's supervision relationships and experiences; Aten, Madson, \& Kruse, 2008), and conducting co-therapy with supervisors-in-training using a reflecting mirror approach (McGee \& Burton, 1998) are additional tools described.

These studies on challenges and strengths of supervision training programs draw from graduate programs that offer short-term workshops or semester- and year-long classes in clinical supervision. During the pre-doctoral clinical internship, there are also opportunities for more senior psychology trainees to begin to supervise a trainee earlier in their development-a component of the psychology training program that is now evaluated during the accreditation process. In addition to the trainee perspectives described above, there are data available from patients receiving psychotherapy by a trainee. One important example of this is a study conducted at a counseling center where services are offered by trainees at the practicum student, intern, and postdoctoral fellow levels in addition to licensed staff (Nyman, Nafziger, \& Smith, 2010). With tiered supervision or supervision-of-supervision ("sup-of-sup") in place, the center has demonstrated improvement in psychological functioning among clients using a validated therapy outcomes questionnaire, the OQ45, regardless of the level of the clinician. In contrast, other literature suggests that having a psychotherapist who possess more experience or more seasoned therapist qualities is associated with better patient outcomes compared to that of novice counselors (Callahan \& Hynan, 2005; Roth, 2003). This area of the literature is complex and given variability in the findings, it is important to continue to evaluate patient outcomes 
across levels of clinician experience and with supervision models in mind.

Within subspecialty fields of psychology, there exists survey research that provides quantitative data as well as a description of the preparation and evaluation of the clinical supervisory role. Among these, neuropsychology has looked at the prevalence of opportunities to learn supervision of assessment. In particular, Shultz, Pedersen, Roper, and Rey-Casserly (2014) described the emphasis on didactics and the focus of supervision for assessment that ensures the development of a broad knowledge base on the part of the trainee. Although many supervision training opportunities appear to exist in training programs, especially within the VA setting (Roper \& Caron, 2012), some surveys have found only a small percentage of trainees have actually gained experience in tiered supervision and learning this new supervisory role (Bowers, Ricker, Regan, Malina, \& Boake, 2002). This may be changing more recently as Shultz, Pedersen, Roper, and Rey-Casserly (2014) reported that a slight majority or $54 \%$ of respondents indicated that they had had experience with tiered supervision. These authors also make the salient point that psychotherapy supervision is more process-focused and distinct from the more didactic approach within their neuropsychology subfield. Similar to the field more broadly, this introduces the idea that there may be more need for self-awareness, critical reflection, and trust when we explore further the qualities of effective supervision for clinical psychology or psychotherapy.

While these perspectives from patients and trainees are valuable, opinions from experienced supervisors are also important and have been examined perhaps the least. One study conducted in Sweden surveyed both supervisor trainees and supervisors. Perspectives from the 2-year, part-time, psychodynamically-oriented supervisory training course revealed that both supervisors and trainees perceived the training as providing adequate knowledge and skills to perform psychotherapy supervision (Sundin, Ögren, \& Boalt Boëthius, 2008). Another Swedish study conducted to document experiences of both "super-supervisors" and supervisees learning to become supervisors highlighted three key themes: 1) developing a supervisor style, 2) non-authoritarian stance, and 3) containment (Ögren, Boalt Boëthius, \& Sundin, 2008). These findings are promising given that, historically, there is a sense that the supervisory role is something psychologists have learned as "trial by fire", as some have described they moved from one side of the table to the other the next day (Amundsen \& McAlpine, 2009). Amundsen and McAlpine asked three questions about the supervisory experience in academic settings and found that participants identified the ways in which they learned to be a supervisor as learning from: 1) the experience as a student; 2) the experience as a supervisor, and 3) colleagues. Moreover, becoming a clinical supervisor has also been described as "role shock" as new supervisors struggle with new role boundaries and definitions and feelings of being overwhelmed, anxious, and uncertain of one's competence and identity as a supervisor (Watkins Jr., 1994).

Another broad research program in Canada was conducted to investigate the 
experiences of both doctoral students and the academic staff who provide supervision (Frick \& Glosoff, 2014). This program ultimately seeks to inform and guide doctoral program curriculum and policies-a welcomed contribution. The evaluators administered questionnaires and interviews asking about learning from experience and learning from colleagues who were also supervising. "Learning through asking questions," "listening and observing," "giving and receiving feedback," "learning from mistakes," and "reflecting" were themes that emerged from their qualitative analyses. These themes suggest the process of preparing to and becoming a clinical supervisor is iterative, experiential, and occurs over time as distinct from more didactic, content-oriented training that takes place in a time-limited workshop. Furthermore, the themes of "learning from mistakes" and "reflecting" underscore the importance of having supportive contexts in which one can learn and practice new skills without fear of reprisal.

As reviewed, much of the literature describes important themes without commenting about the effectiveness of providing these elements to trainees. Moreover, the themes indicate guidance on how to provide these elements is needed. It may be that independent programs, which provide continuing education to mental health fields (e.g., Courses for Mental Health Professionals, 2016; PESI, 2016), offer some structure of support and are a much needed resource. Such guidance may also take place through mentoring relationships that range from informal to more formal programs with matching mentors to mentees. Across graduate training programs and settings there is likely a myriad of approaches to guide licensed clinicians and trainees on how to become an effective clinical supervisor. One national sample of clinical supervision practices provided statistics on the amount of time spent providing supervision and the modalities used (group, individual, in-person, etc.), but the authors did not investigate the faculty members' viewpoints on their preparation for this role (Tyler, Sloan, \& King, 2000). Interestingly, these authors commented on the significant additional professional time, commitment, and responsibilities providing supervision necessitates. Thus, despite its relevance including the time commitment, little standardization of preparation appears to exist.

Given minimal guidance from within the field, following a quality improvement paradigm and looking to other professions may offer valuable perspectives. First, the health professions field more broadly and medicine more specifically can offer guidance with its tradition of reflection. Mann, Gordon, and MacLeod (2009) summarized the history of definitions and models of practice of reflection with the following common themes or elements:

- intellectual and affective activity to explore one's experiences which leads to new understanding,

- active, ongoing consideration of one's beliefs and knowledge,

- mental processing that is applied to relatively complex or unstructured ideas, and,

- knowing-in-action when action is not routine. 
From an applied sense, Aronson (2011) outlined 12 practical steps for setting up and implementing self-reflective practices in the healthcare setting. These range from defining reflection, its methods, and the practice itself, to allocating time and creating psychological safety in order to implement the practice of reflection as an ongoing effort. Aronson begins with a definition of reflection on experience and one's professional actions in a manner that supports insight and taking further action to enhance one's performance. These tips also clarify the importance of psychological safety and creating an environment conducive for learning. Additionally, for this process to be effective, Aronson's guidelines articulate the need to allocate time for reflection on experience and providing feedback.

\section{Two Proposed Models}

The health professions more broadly, as well as the fields of business and sports, have a significant history of providing training for leadership, consultation, and coaching roles that foster professional development (e.g., Gawande, 2011). There appears to be a tradition espousing coaching models that point to the process of continuous improvement and learning new roles and skill sets within a field. As Gawande explained, there is an understanding that the science of medicine and healthcare is always evolving. Therefore, improving continually on one's skills and receiving feedback are vital. The process of learning a new psychotherapy, based on the latest research evidence, and refining one's clinical skills similarly include consultative or coaching processes. In one particular coaching model, specified training is conducted first in a two- to three-day workshop followed by a structured 6-month consultative process. The Veteran's Administration Central Office (VACO) has been instrumental with the dissemination of evidenced based psychotherapy (EBP) rollouts that utilize several common processes when training clinicians, consultants, and Master Trainers. Consider the parallels between EBP tiers of training: Master Trainer $\rightarrow$ consultants $\rightarrow$ trainees in training; and then the reciprocal process of "trained/competent" trainee $\rightarrow$ consultants $\rightarrow$ Master Trainer. This framework has been evaluated in terms of its success in implementing the use of new and established psychotherapies, which has furthered the evidence based movement, insured fidelity of the interventions, and supported greater accountability in our field. In this program, there have been "train the trainer" workshops, which train licensed clinicians to take on a new trainer role. It offers opportunities for giving and receiving feedback as well as a check-and-balance experience as the clinician takes on the new "trainer" role of training other clinicians in the EBP.

Problem Solving Training (PST) is one evidenced based psychotherapy that has been widely used in the VA and the focus of many trainings. As we examine the specifics of the PST dissemination across the VA, we can identify the interactive tiered model in play. Tenhula et al. (2013) outlined the training/consultation/trainee process utilized in the dissemination of PST. During a two-and-a-half-day 
face-to-face workshop, a combination of didactic presentations, intensive training, clinical demonstrations, and role playing regarding the principles and application of PST were employed. Consultation calls led by PST experts (e.g. Master Trainers [Tier 1]) occurred once weekly. Not only did trainees (Tier 3) experience small-group practice implementing the curriculum, they were provided immediate feedback from the Master Trainers and consultants. Consultants in training, Tier 2 (with Master Trainers on calls [Tier 1]) provided weekly consultation providing logistical support, adherence to the treatment, and real-time feedback regarding application as well as focusing on process. This tiered model is practical at each level and not unlike the learning of clinical supervision. Importantly, this role and process requires skills distinctly different from acquiring the skills specific to the direct application of the psychotherapy. There exists less systematically graduated levels of experience when learning to become a clinical supervisor, but we suggest that those could be obtained through a tiered modality of training. With this framework and levels of feedback and support, the new trainer can gain confidence and competence and hopefully prevent a "trial by fire" in their new role.

Related to the PST "train the trainer" model is the VHA National Center for Health Promotion and Disease Prevention (NCP) "Coaching the Coach" model. Beginning in 2012, NCP developed and implemented a clinician coaching skills training course (Goldstein, 2012). The course was designed to assist clinicians, who are predominantly licensed psychologists, carry out their new role as a Health Behavior Coordinator (HBC) or health coach to other healthcare clinicians. Building on prior learning and skills sets, the two-and-a-half-day initial training offers experiential learning with role plays that focus on practicing the skill of coaching another clinician who is learning to be a health coach. The tiers or multiple roles of this process were made explicit, and reflection and processing occurs in between each role play. The emphasis was on the psychologist learning their new "Coaching the Coach" role, yet participants took part in all roles and aspects of the model. Similar to the PST roll-out described above, ongoing consultation occurs following the two-and-a-half-day training as the clinicians return to their worksites and carry out the new role.

An analogous process for clinical supervision would be to have role plays, small group discussions, peer consultation, and reflection among clinical psychologists learning the new role and their mentors and trainees/supervisees (see Figure 1). In a time-delineated training, these roles and role plays could be practiced (steps 2 and 3, Figure 1). Step 2 makes explicit the role of supervisor and focuses on input and feedback with the supervisee (as distinct from the patient). Importantly, Steps 1, 4, and 5 provide dedicated time for reflection (Figure 1). In both models described, these steps can take place over time as well, following a one-time workshop. Alternatively, all these steps can occur within the context of one's work without a distinct workshop. Regardless of the structure, this brings to mind the importance of leadership investment and commitment to 
"Coaching the Coach" -

for clinical supervision role

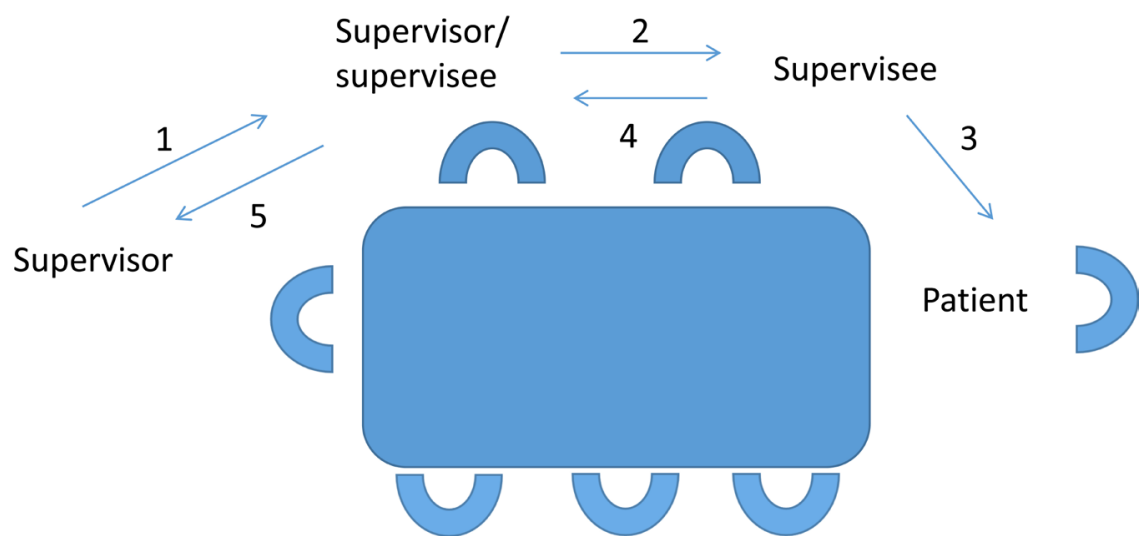

Figure 1. "Coaching the coach/clinical supervisor" model.

prioritizing this learning and protecting professional work time for these activities, as Aronson (2011) highlighted among the 12 practical steps.

To describe the ongoing process further, the follow-up to NCP training occurs for the HBCs with monthly, more formal nation-wide teleconferences, which highlight best practices in implementation. These calls are audiotaped and shared on a national "Sharepoint" along with a plethora of resources to support HBCs in their roles, including a "Coaching the Coach" video series, which was produced and distributed for use at all national sites. The video demonstrates the role of "Coaching the Coach" or supervising the trainee (Step 2, Figure 1). There are also regional subgroup meetings and collaboration with other prevention-related roles and more targeted projects. Informally, networking and other forms of collaboration are highly encouraged. From this national leadership, psychological safety and empowering the HBCs in their roles is very much evident. Moreover, a parallel process is promoted, between teaching motivational interviewing (MI) and other health coaching skills to clinicians and using these same skills with colleagues, in order to develop health promotion, disease prevention programs. In fact, leadership has modeled MI-consistent communication and behavior on the teleconferences continuously.

\section{Conclusion}

This paper first described data from the existing literature which reveals a need for frameworks and processes to guide psychologists in learning and teaching the distinct professional role of clinical supervision. We then presented a train-the-trainer model and a coaching-the-coach model that we believe provide practical guides for licensed clinicians and trainees to learn, practice and gain confidence in their new clinical roles. Both models create opportunities for participants to build trusting alliances in which they can provide and receive feedback without reprisal. It would be powerful to implement a broad, national initiative analogous to the VA training programs. The goal would be to imple- 
ment a similar effort that could "de-mystify" or make explicit the clinical supervisory role and process to support trainees and clinical psychologists in their professional development and prevent the "role shock" or "trial by fire".

The two aforementioned VA models have been implemented and sustained successfully with the VA healthcare organization. They portray an experience of scaffolding and ongoing reflection in their processes. In between supervision sessions, the new supervisor can reflect on which behaviors to continue and which to modify or stop. Furthermore, as with motivational interviewing, reflections (with oneself and from a trusted other) serve to instill and enhance self-confidence in one's own ability to perform in their new supervisory role. Having an explicit structure and process is paramount in order for this to take place and to create the psychological safety that is fundamental. Given APIC's (2016) specificity of requirements that psychology interns demonstrate proficiency in the area of clinical supervision, utilizing models of tiered supervision with leadership investment seems a priority. In these programs, modeling, role-playing, and didactics are assimilated in workshops, and with an ongoing framework and process in order to support practice and integration of new skills. Throughout, reflection is encouraged and modeled in order to create psychological trust. This trust creates an environment where clinicians gain confidence in their new role, which can optimize effective provision of clinical supervision and in turn effective psychotherapy-ultimately benefiting patients.

\section{References}

Amundsen, C., \& McAlpine, L. (2009). “Learning Supervision”: Trial by Fire. Innovations in Education and Teaching International, 46, 331-342. https://doi.org/10.1080/14703290903068805

Aronson, L. (2011). Twelve Tips for Teaching Reflection at All Levels of Medical Education. Medical Teacher, 33, 200-205. https://doi.org/10.3109/0142159X.2010.507714

American Psychological Association. (2014). Guidelines for Clinical Supervision in Health Service Psychology. http://apa.org/about/policy/guidelines-supervision.pdf

American Psychological Association. (2015). Standards of Accreditation for Health Service Psychology. https://www.apa.org/ed/accreditation/about/policies/standards-of-accreditation.pdf

Aten, J. D., Madson, M. B., \& Kruse, S. J. (2008). The Supervision Genogram: A Tool for Preparing Supervisors-in-Training. Psychotherapy, 45, 111-116. https://doi.org/10.1037/0033-3204.45.1.111

Bernard, J. M. (2014). The Use of Supervision Notes as a Targeted Training Strategy. American Journal of Psychotherapy, 68, 195-212.

Borders, L. D., \& Fong, M. L. (1994). Cognitions of Supervisors-in-Training: An Exploratory Study. Counselor Education and Supervision, 33, 280-293. https://doi.org/10.1002/j.1556-6978.1994.tb00294.x

Bowers, D. A., Ricker, J. H., Regan, T. M., Malina, A. C., \& Boake, C. (2002). National Survey of Clinical Neuropsychology Postdoctoral Fellows. The Clinical Neuropsychologist, 16, 221-231. https://doi.org/10.1076/clin.16.3.221.13847

Callahan, J. L., \& Hynan, M. T. (2005). Models of Psychotherapy Outcome: Are They Ap- 
plicable in Training clinics? Psychological Services, 2, 65-69.

https://doi.org/10.1037/1541-1559.2.1.65

Courses for Mental Health Professionals. (2016). http://www.continuingedcourses.net/active/index.php

Duffy, J. T., \& Guiffrida, D. A. (2014). The Heroic Supervisor: Using the Hero's Journey to Facilitate Development in Supervisors-in-Training. The Clinical Supervisor, 33, 144-162. https://doi.org/10.1080/07325223.2014.978587

Ellis, M. V. (2006). Critical Incidents in Clinical Supervision and in Supervisor Supervision: Assessing Supervisory Issues. Training and Education in Professional Psychology, $S$, 122-132. https://doi.org/10.1037/1931-3918.S.2.122

Frick, M. H., \& Glosoff, H. L. (2014). Becoming a Supervisor: Qualitative Findings on Self-Efficacy Beliefs of Doctoral Student Supervisors-in-Training. The Professional counselor, 4, 35-48. https://doi.org/10.15241/mhr.4.1.35

Gawande, A. (2011). Top Athletes and Singers Have Coaches. Should You? [Annals of Medicine] The New Yorker.

http://www.newyorker.com/magazine/2011/10/03/personal-best

Gazzola, N., De Stefano, J., Thériault, A., \& Audet, C. T. (2013). Learning to Be Supervisors: A Qualitative Investigation of Difficulties Experienced by Supervisors-in-Training. The Clinical Supervisor, 32, 15-39.

https://doi.org/10.1080/07325223.2013.778678

Gazzola, N., De Stefanob, J., Theriault, A., \& Audet, C. (2014). Positive Experiences of Doctoral-Level Supervisors-in-Training Conducting Group-Format Supervision: A Qualitative Investigation. British Journal of Guidance \& Counselling, 42, 26-42. https://doi.org/10.1080/03069885.2013.799263

Goldstein, M. G. (2012). Clinician Coaching, Facilitation, and Presentation Skills for TEACH and MI Facilitators (Vol. Version 3). New Haven, CT: VHA National Center for Health Promotion and Disease Prevention (NCP).

Majcher, J., \& Daniluk, J. C. (2009). The Process of Becoming a Supervisor for Students in a Doctoral Supervision Training Course. Training and Education in Professional Psychology, 3, 63-71. https://doi.org/10.1037/a0014470

Mann, K., Gordon, J., \& MacLeod, A. (2009). Reflection and Reflective Practice in Health Professions Education: A Systematic Review. Advances in Health Sciences Education: Theory and Practice, 14, 595-621. https://doi.org/10.1007/s10459-007-9090-2

McGee, M., \& Burton, R. (1998). The Use of Co-Therapy with a Reflecting Mirror as a Supervisory Tool. Journal of Family Psychotherapy, 9, 45-60. https://doi.org/10.1300/J085V09N04_04

Nyman, S. J., Nafziger, M. A., \& Smith, T. B. (2010). Client Outcomes across Counselor Training Level within a Multitiered Supervision Model. Journal of Counseling \& Development, 88, 204-209. https://doi.org/10.1002/j.1556-6678.2010.tb00010.x

Ögren, M., Boalt Boëthius, S., \& Sundin, E. C. (2008). From Psychotherapist to Supervisor. Nordic Psychology, 60, 3-23. https://doi.org/10.1027/1901-2276.60.1.3

Okafor, E., Wojciak, A. S., \& Helfrich, C. M. (2014). Unheard Voices: The Experiences of Supervisors in Training. Contemporary Family Therapy, 36, 369-379.

https://doi.org/10.1007/s10591-013-9295-x

PESI (2016). Continuing Education. http://www.pesi.com/

Roper, B. L., \& Caron, J. E. (2012). Training and Supervision in Neuropsychology within the Department of Veterans Affairs. In S. S. Bush (Ed.), Neuropsycological Practice with Veterans (pp. 281-303). New York: Springer. 
Roth, S. A. (2003). A Program Evaluation Measuring the Effectiveness of Service Delivery at a University Counseling Setting. Doctoral Dissertation, Retrieved from DigitalCommons@Pace. (AAI3073665)

Shultz, L. A., Pedersen, H. A., Roper, B. L., \& Rey-Casserly, C. (2014). Supervision in Neuropsychological Assessment: A Survey of Training, Practices, and Perspectives of Supervisors. The Clinical Neuropsychologist, 28, 907-925. https://doi.org/10.1080/13854046.2014.942373

Sudak, D. M., Codd III, R. T. C., Ludgate, J., Sokol, L., Fox, M. G., Reiser, R., \& Milne, D. L. (2015). Teaching and Supervising Cognitive Behavioral Therapy. Hoboken, NJ: John Wiley \& Sons. https://doi.org/10.1002/9781119179948

Sundin, E. C., Ögren, M.-L., \& Boalt Boëthius, S. (2008). Supervisor Trainees' and Their Supervisors' Perceptions of Attainment of Knowledge and Skills: An Empirical Evaluation of a Psychotherapy Supervisor Training Programme. The British Journal of Clinical Psychology, 47, 381-396.

Tenhula, W. N., Nezu, A. M., Nezu, C. M., Stewart, M. O., Miller, S. A., Steele, J., \& Karlin, B. E. (2013). Moving Forward: A Problem-Solving Training Program to Foster Veteran Resilience. Professional Psychology Research and Practice, 45, 416-424. https://doi.org/10.1037/a0037150

Tyler, J. D., Sloan, L. L., \& King, A. R. (2000). Psychotherapy Supervision Practices of Academic Faculty: A National Survey. Psychotherapy: Theory, Research, Practice, Training, 37, 98-101. https://doi.org/10.1037/h0087750

Watkins Jr., C. E. (1994). The Supervision of Psychotherapy Supervisor Trainees. American Journal of Psychotherapy, 48, 417-431. 